\title{
Radiological Assessment of Middle Ear Subtensor Recess: A Morphological Study by High-resolution CT Scan
}

\section{José Luis Treviño-González MD PhD ${ }^{1 *}$, Guillermo González-Dávila MD², German A Soto-Galindo $\mathrm{MD}^{2}$ and Daniel Alejandro Aranda-García MD $^{2}$}

${ }^{1}$ Chief of Otolaryngology - Head and Neck Surgery Department, University Hospital, Monterrey, Mexico

${ }^{2}$ Otolaryngology - Head and Neck Surgery Department, University Hospital,

Monterrey, Mexico

*Corresponding Author: Jose Luis Treviño González, Chief of Otolaryngology Head and Neck Surgery Department, University Hospital, Monterrey, Mexico.
Received: November 30, 2021

Published: December 31, 2021

(C) All rights are reserved by Jose Luis

Treviño González., et al.

\begin{abstract}
Objective: The aim of the study was analyze the anatomical variants of the subtensor recess in the middle ear based on an ear sagittal and axial thin-section noncontrast-computed tomography.

Methods: The study sample, between May 2018 and December 2019, consisted on a retrospective review of 102 imaging studies, giving a total of 204 ears, the presence of 3 variants was determinated. These variants were: recess type A (absence), type B (shallow recess) and type $C$ (deep recess).

Results: 204 ears were analyzed by simple ear computed tomography in thin sagittal and axial sections, finding a subtensor recess of the middle ear type A in $39.2 \%$ of the population, recess type B in $25 \%$ and recess type C in $35.8 \%$. No significant differences were found $(\mathrm{p}<0.05)$ in the comparison of age, sex, or comorbidities between analyzed groups.

Conclusion: A prevalence of type C recess of $35.8 \%$ of the population was observed, showing a high prevalence, having a direct impact on the surgical approach to the middle ear, making the preoperative assessment by CT-scan essential, it is a challenge because the surgical technique used will be of utmost importance for proper treatment and to avoid disease recurrences.
\end{abstract}

Keywords: Subtensor Recess; Middle Ear; Radiology; Protympanum; Anatomical Variants

\section{Introduction}

The middle ear can be divided into different subregions which include the hypotympanum, mesotympanum, and epitympanum, whose limits are defined mainly by their position respect to the tympanic annulus [1].

The mesotympanum is the space comprised medially to the tympanic membrane, extending anteriorly to the Eustachian tube and posteriorly to the facial nerve. The hypotympanum is delimited superiorly by the tympanic annulus, inferiorly by the jugular bulb and inferomedial by the cochlea [1,2].
The epitympanum is the space above an imaginary line passing through the short process of the hammer, laterally limited by the Shrapnell membrane, medially by the lateral semicircular canal and posterior by the region of the aditus ad antrum [3].

The protympanum, or bony portion of the Eustachian tube, is a space of the middle ear that lies anterior to the mesotympanum, converges superiorly with the epitympanum, inferiorly with the hypotympanum, and anteriorly with the cartilaginous portion of the Eustachian tube. 
The tubular canal of the tensor tympanum comprises one of the upper limits of the protympanum, sometimes it can present inferomedial pneumatization, known as subtensor recess, and may have 3 possible conformations based on its depth: [4]

- Type A: Flat tensor canal, absence of subtensor recess.

- $\quad$ Type B: Raised tensor canal, shallow subtensor recess with an easily visible bottom.

- $\quad$ Type C: Raised tensor canal, deep subtensor recess, difficulty to visualize the bottom.

The difference between type $B$ and type $C$ is that the bottom of the recess exceeds the midpoint of the tensor tympani canal. Currently, with the new classification given by Jufas, N., et al. of the subtensor recess of the middle ear, the aim is to find the prevalence of the different types of recess in pre-surgical planning to choose the most appropriate technique in case that an intervention is required [4].

The general conformation of the protympanum can be quadrangular or triangular in a two-dimensional plane perpendicular to the long axis of the Eustachian tube [5].

The protympanum can also contain multiple air cells, defined as discrete blind spaces within it. They are located predominantly posteroinferomedial, which implies that they can be pneumatized in the protympanum from hypo-tympanic cells. Bony spicules are occasionally present on the protympanum, particularly in the prominence of the carotids. Occasionally, the bone spicules can join in a linear formation making it difficult to visualize the entire cavity $[5,6]$.

One of the main etiologic factors in the development of cholesteatoma is the long-term dysfunction of the Eustachian tube [7].

Otitis media has been shown to occur correlated to different diseases. Eustachian tube obstruction leads to progressive inflammatory changes in the cleft of the middle ear; if the obstruction is not resolved, the formation of intractable changes in the middle ear, such as granulation tissue, cholesterol granuloma, and cholesteatoma, is often explained [7].

As an ear progresses from developing Eustachian tube dysfunction to developing chronic otitis media, a well-documented sequence of histopathological changes in the middle ear is known to occur, including mucous edema with a widening of the subepithelial space, vascular dilation, and leukocyte infiltration [8].

The divisions and subdivisions of the middle ear can be evaluated with imaging studies such as computed tomography or by surgical techniques as endoscopy and microscopy, showing the importance of the analysis of their variants to know the best approach, individualizing each case for an optimal result [9].

Ear surgery, specifically, surgery for chronic cholesteatomatous otitis media, is a complex surgery, it requires an approach with resection of the posterior wall of the ear canal to have a broad view of the cavity. It is recommended to perform a resection of the surrounding bone of the facial nerve to reduce the incidence of recurrent cholesteatoma and for complete exposure [10].

The anatomical subdivision of the middle ear presents a high degree of complexity for the different surgical approaches because the correct visualization of all the structures is operator dependent [11].

It is necessary to know the anatomical subdivisions perfectly regardless of the pathology to be treated because this will make us perform a more complete surgery reducing the possibilities of reoperations for recurrences, which are reported in the literature approximately in $11 \%-27 \%$ of the cases [12].

If a hypovolumetric anterior epitympanum recess occurs, it could be a congenital morphological condition that predisposes to the presence of cholesteatoma despite adequate aeration of the epitympanic compartment, on the contrary, the presence of membranous and/or ligamentous folds could exclude the anterior epitympanic recess of the posterior epitympanic space and the protympanum. The predisposition to lack of tactical ventilation should be clarified in more studies [13].

It has been shown that the cholesteatomas that cover these recesses are better visualized by endoscopic techniques than by microscopic techniques, here is the importance of prior evaluation of imaging studies to perform the most appropriate technique according to the anatomical variant presented by the patients [14].

A description given by Jufas, N., et al. in 2017 through a morphological anatomical study by endoscopy, a prevalence of conformation of the subtensor recess type A of $29.9 \%, 48.5 \%$ of type B and 
$21.6 \%$ of type $\mathrm{C}$ was found, $20 \%$ of the rest of the patients could not be evaluated due to the difficulty of visualization by the surgical technique used $[15,16]$.

\section{Materials and Methods}

This is a retrospective and descriptive study, we included ear thin-section noncontrast-computed tomographies of the patients seen at the University Center for Otorhinolaryngology and head and neck surgery of the University Hospital “Dr. José Eleuterio González ", UANL, Monterrey, Nuevo León, Mexico, for any otic pathology, which were performed at the same institution in the diagnostic imaging service. The subsequent analysis of the same was carried out in conjunction with the diagnostic radiology service of the same institution.

The imaging studies to select consist of high-resolution computed tomography scans with special attention in the ear with thinsections $(0.5 \mathrm{~mm})$.

The variants studied were those described by Jufas N., et al. [5], consist in variants of the subtensor recess classified into 3 types depending on the depth of the recess seen by image study, type $\mathrm{A}$ recess which shows the absence of pneumatization, type $B$ recess with a raised tensor canal and a superficial recess with visible bottom and type $\mathrm{C}$ recess with a raised tensor canal, deep and difficult to visualize bottom limits.

The study was carried out at the Otorhinolaryngology and Head and Neck Surgery Service of the University Hospital "Dr. José Eleuterio González", UANL. We collected 102 computed topographies, resulting in the study of 204 ears, obtaining a significant sample.

The study values are classified according to the type of subtensor recess in A, B, or C, and the proportions were compared with patients variables by hypothesis testing techniques for means and proportions with a confidence interval of $95 \%$.

\section{Results}

204 ears were studies, Type A recess was the most prevalent recess in this study, being found in $39.2 \%$ of the analyzed studies with a total of 80 ears; 39 males with type A recess and 41 females.

Type B recess was the least prevalent, it was found in $25 \%$ of the study population with a total of 51 ears; 22 males with type B recess and 29 females.
Type $\mathrm{C}$ recess was the second in prevalence, being in $35.8 \%$ with a total of 73 patients; 31 males with type $C$ recess and 42 females, the female sex having a higher prevalence in this type of recess, this being relevant since for surgical purposes this type of recess is the most complex in terms of management.

The rest of the variants were analyzed, such as, the reason for consultation, previous diagnosis, medical history, surgical history, comorbidities, looking for any relevance correlated with the type of recess that was had, but no statistically significant association was found with them.

Age groups were compared, since it is well established that the pneumatization of the craniofacial bones depends on the age of the patients, in pediatric ages (5-10 years the pneumatization is completed) there may be areas that are not well pneumatized, which progress with age, no statistically significant differences were found in terms of pneumatization in pediatric patients vs young or older patients.

The anatomical variants related to sex were analyzed looking for relevance because the literature shows a higher incidence of chronic otitis media in women, in type A and type $B$ recesses no significant difference was found in the comparison, but in type $\mathrm{C}$ recesses, a difference was found in the prevalence between men and women, since the female sex presented a higher prevalence, this being relevant since it gives us indications that this type of anatomical variant may make the female sex prone to the development of chronic otitis media and its subsequent complications if proper surgical management is not given.

\section{Discussion}

The most relevant findings in this study were to find the prevalence of the different types of subtensor recess by image study, this to have a morphological analysis of the northeast Mexican population to subsequently correlate its medical and surgical implications.

Jufas, N., et al. in 2017 carried out a morphological study of the subtensor recess by endoscopy, presenting data that contrasts with the obtained by our study, they performed it with a smaller sample $(\mathrm{N}=97 \mathrm{vs} \mathrm{N}=204)$, their results compared to ours were the following: type A recess $29.9 \%$ vs. $39.2 \%$, type B recess $48.5 \%$ vs. $29.1 \%$ and type $\mathrm{C}$ recess $20 \%$ vs. $35.8 \%[5,15]$. 
The correlation with the degree of ear pneumatization according to age and sex did not show significant results.

The prevalence observed in the type $\mathrm{C}$ recess was $35.8 \%$ compared to the type A prevalence of $39.2 \%$, this being a deep recess which makes the surgical approach difficult, having to use endoscopic lenses to allow access to it [4]. This type of recess is prone to presenting residual disease requiring a different surgical technique than the conventional ones, so prior analysis through an imaging study is important to carry out the appropriate surgical technique for better resolution of the inflammatory process. in the middle ear [9].

\begin{tabular}{|c|c|c|}
\hline Subtensor Recess type & Frequency & Percentage \\
\hline Type A & 80 & $39.2 \%$ \\
\hline Type B & 51 & $25 \%$ \\
\hline Type C & 73 & $35.8 \%$ \\
\hline Total & 204 & $100 \%$ \\
\hline
\end{tabular}

Table 1: Types of recess and their frequency.

\begin{tabular}{|c|c|c|}
\hline Gender & Frequency & Percentage \\
\hline Female & 110 & $53.9 \%$ \\
\hline Male & 94 & $46.1 \%$ \\
\hline Total & 204 & $100 \%$ \\
\hline
\end{tabular}

Table 2: Sample divided into gender.

\begin{tabular}{|c|c|c|}
\hline Age group (years) & Frequency & Percentage \\
\hline Children $(0-11)$ & 26 & $12.7 \%$ \\
\hline Teenagers $(12-20)$ & 30 & $14.7 \%$ \\
\hline Adults $(20-59)$ & 108 & $52.9 \%$ \\
\hline Older adults $(>60)$ & 40 & $19.6 \%$ \\
\hline Total & 204 & $100 \%$ \\
\hline
\end{tabular}

Table 3: Classification of sample according to age group.

\begin{tabular}{|c|c|c|c|}
\hline Clinical diagnosis & Type A & Type B & Type C \\
\hline Chronic medium otitis & 30 & 25 & 31 \\
\hline & $34.9 \%$ & $29.1 \%$ & $36 \%$ \\
\hline
\end{tabular}

Table 4: Clinical diagnosis (chronic otitis media) and its prevalence.

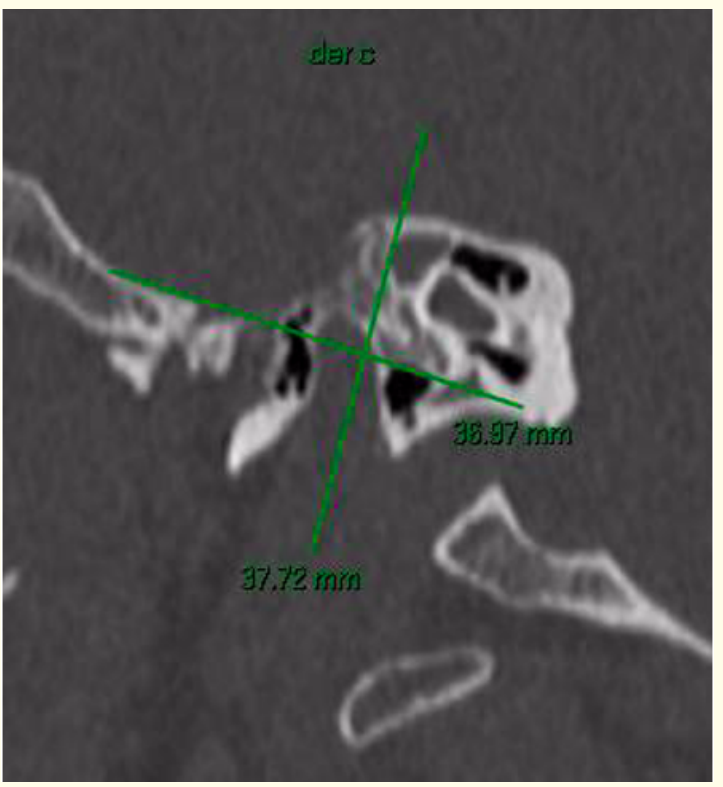

Figure 1: Sagittal reconstruction of a noncontrasted-computed tomography of the right ear showing a type $\mathrm{C}$ subtensor recess.

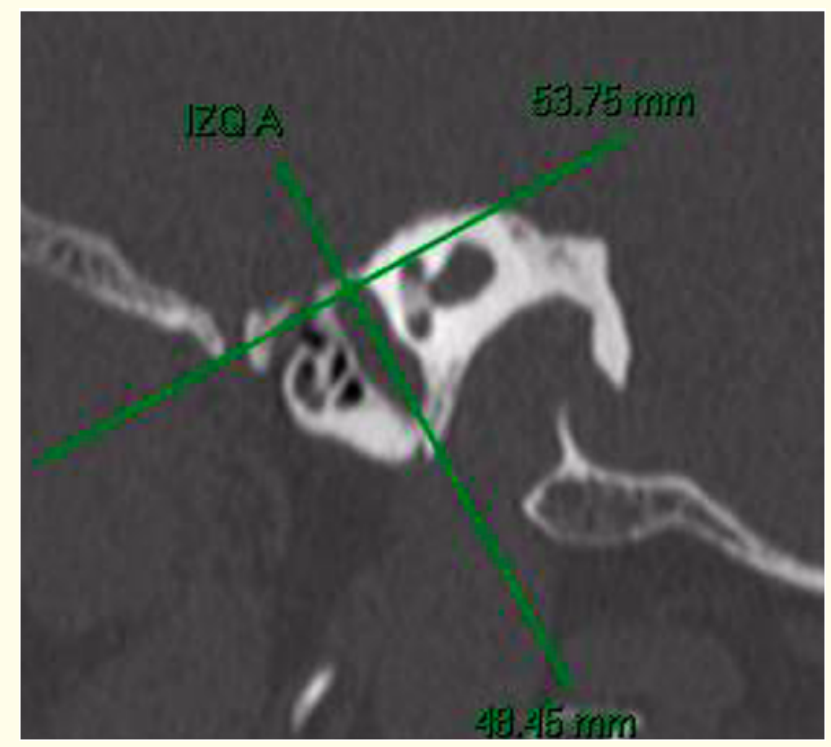

Figure 2: Sagittal reconstruction of a noncontrasted-computed tomography of the left ear showing a type A subtensor recess. 


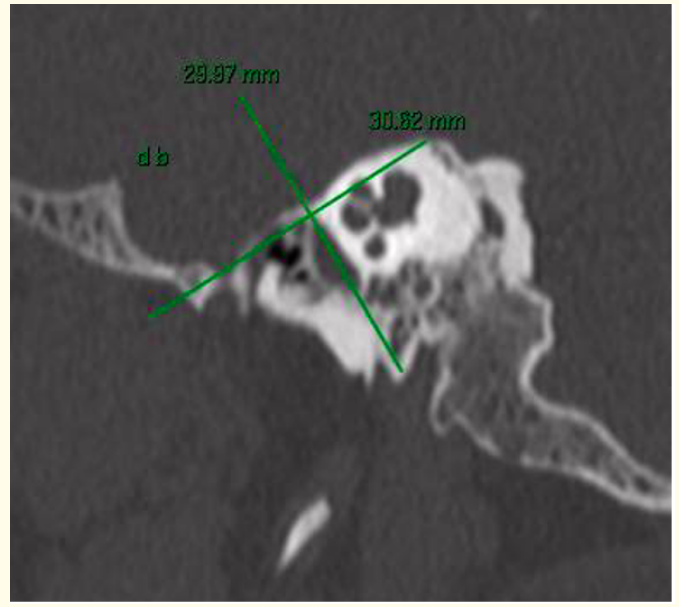

Figure 3: Sagittal reconstruction of a noncontrasted-computed tomography of the right ear showing a type B subtensor recess.

\section{Conclusion}

A high prevalence of type $C$ recess was identified, having a direct impact on the surgical approach to the middle ear, making the preoperative assessment by CT-scan essential.

Knowing the anatomical variants of the subtensor recess of the middle ear through an imaging study allows planning the appropriate surgical treatment.

\section{Bibliography}

1. Bailey B., et al. "Head and neck surgery-otolaryngology". $1^{\text {st }}$ ed. Philadelphia, PA: Lippincott Williams and Wilkins (2006):1981-1984.

2. Tóth M., et al. "Development of the protympanum". Annals of Anatomy - Anatomischer Anzeiger 188.3 (2006):267-273.

3. "Comprehensive and clinical anatomy of the middle ear". $\mathrm{Na}$ ture (2019):92-100.

4. Jufas N., et al. "Endoscopic Anatomy of the Protympanum". Otolaryngologic Clinics of North America 49.5 (2016):1107-1119.

5. Jufas N., et al. "The protympanum, protiniculum and subtensor recess: an endoscopic morphological anatomy study". Journal of Laryngology and Otology (2018):1-4.
6. Ars B and Dirckx J. "Eustachian Tube Function". Otolaryngologic Clinics of North America 49.5 (2016):1121-1133.

7. Pauna H., et al. "A 3-D analysis of the protympanum in human temporal bones with chronic ear disease". European Archives of Oto-Rhino-Laryngology 274.3 (2016): 1357-1364.

8. Christov F and Gluth M. "Histopathology of the Mucosa of Eustachian Tube Orifice at the Middle Ear in Chronic Otitis Media With Effusion: Possible Insight Into Tuboplasty Failure". Annals of Otology, Rhinology and Laryngology 127.11 (2018): 817-822.

9. Hildmann H and Sudhoff H. "Middle Ear Surgery". (2016): 6770.

10. Arnoldner C., et al. Manual of Otologic Surgery 35-38.

11. Albera R., et al. "Condition of the anterior part of the middle ear cleft in acquired cholesteatoma". Acta Oto-Laryngologica 128.6 (2018): 634-638.

12. Flint P. "Cummings Otorrinolaringology head and neck surgery". Phyladelphia, USA: Elsevier (2015).

13. Marchioni D., et al. "CT morphological evaluation of anterior epitympanic recess in patients with attic cholesteatoma". European Archives of Oto-Rhino-Laryngology 266.8 (2008): 1183-1189.

14. Gacek R. "Ear surgery". Berlin: Springer (2008):55-60.

15. Dunnebier E., et al. "Imaging for otolaryngologists". (2011): 12-22.

\section{Assets from publication with us}

- Prompt Acknowledgement after receiving the article

- Thorough Double blinded peer review

- Rapid Publication

- Issue of Publication Certificate

- High visibility of your Published work

Website: www.actascientific.com/

Submit Article: www.actascientific.com/submission.php Email us: editor@actascientific.com

Contact us: +919182824667 